\title{
A Novel Concept of Phase Swapping for Multiple Enhanced Speed Operations of a PM machine using Winding Switching
}

\author{
Shahid Atiq*, Asif Hussain** and Byung-il Kwon ${ }^{\dagger}$
}

\begin{abstract}
This paper presents a novel concept of phase swapping to associate multiple flux weakening ranges to a non-salient PM machine without altering any hardware of the machine. The proposed concept enables a dual three-phase machine to be operated with different displacement angles between the two three-phase windings. Hence, different flux weakening ranges using winding switching can be accomplished by applying this concept. It was also demonstrated that the proposed concept can be utilized for the discrete step as well as continuous operation of the machines. Any application requiring a wide speed range operation of up to thirteen times the base speed can benefit from this proposed concept. Analytical, simulation, and experimental results are provided to validate the effectiveness of the proposed concept.
\end{abstract}

Keywords: Phase swapping, Winding switching, Dual inverter, Discrete operation, Continuous operation

\section{Introduction}

Wide speed range operation of electrical machines is a common requirement of modern sophisticated loads including electric and hybrid vehicles. Permanent magnet (PM) machines are very popular in modern industry due to their compact size, high power density, high torque to inertia ratio, and high efficiency. However, PM machines utilize PMs on their rotors which result in a constant rotor excitation. Therefore, the back EMF of these machines becomes significant under high speed operation which limits the maximum achievable speed with a limited inverter voltage. Flux weakening becomes inevitable in this case to further increase the speed of these machines. The flux weakening capability of PM machines, on the other hand, is dependent upon the d-axis inductance [1-3]. Generally, machine designers have to design a PM machine with a large $\mathrm{d}$-axis inductance to increase its flux weakening capability. However, non-salient PM machines exhibit low inductance characteristics due to their low permeability surface-mounted PMs. Hence, these machines are not considered good candidates for the flux weakening operation.

Concentrated windings demonstrate high inductance characteristics [4, 5] and the authors in $[6,7]$ had researched the flux weakening capability of non-salient PM machines utilizing concentrated winding. However, the concentrated windings have high core losses due to spatial

$\dagger$ Corresponding Author: Dept. of Electronic Systems Engineering, Hanyang University, South Korea. (bikwon@hanyang.ac.kr)

* Dept. of Electrical Engineering, The Islamia University of Bahawalpur, Pakistan. (shahid.atiq@iub.edu.pk)

** Dept. of Electronic Systems Engineering, Hanyang University, South Korea. (asifhussain@hotmail.com)

Received: June 17, 2016; Accepted: October 11, 2016 harmonic contents [8-10]. Pole changing machines have also been studied for extended speed operations [11]. Furthermore, star, delta, series, and parallel connections have been utilized to achieve high speed operations from electrical machines $[12,13]$.

Recently, a dual inverter fed winding switching technique has been proposed for the flux weakening of non-salient PM machines [14-16]. This technique divides the threephase winding of the machine into two equal half windings, resulting in a dual three-phase machine. The flux weakening range of the machine depends upon the displacement angle between the resultant two half windings in this technique. This paper introduces a novel concept of phase swapping to achieve multiple displacement angles between the two half windings without changing any hardware of the machine. Thus, the proposed concept enables a machine to achieve multiple flux weakening ranges and can be utilized in any application. This paper is organized as follows. Section 2 describes the winding switching technique followed by the proposed concept of phase swapping in Section 3. Section 4 presents the analytical, simulation and experiment results of the complete operation of the machine utilizing the phase swapping concept. The conclusions of this work are then presented.

\section{Winding Switching Theory}

The winding of a conventional three-phase machine is divided into two equal half windings, $\mathrm{ABC}$ and $\mathrm{XYZ}$, in this technique. The machine is operated in a cumulative mode before winding switching such that the flux of both half windings add to build the net air gap flux of the machine. The polarity of the XYZ winding is reversed at 
winding switching and the machine operates in a differential mode such that the flux of the XYZ winding subtracts from the flux of the ABC winding. This results in a reduced net air gap flux of the machine. Net voltage drop of the machine can be represented by (1)

$$
V=E+L \frac{d I}{d t}+R I
$$

Where $\mathrm{V}$ is the terminal voltage, $\mathrm{E}$ is the back EMF, I is the phase current, $\mathrm{L}$ and $\mathrm{R}$ are the winding inductance and resistance respectively.

The back EMFs of phase-A from the $\mathrm{ABC}$ winding and phase-X from the $\mathrm{XYZ}$ winding are represented by (2) and (3), respectively.

$$
\begin{gathered}
E_{a}=E \sin \left(\omega_{e} t\right) \\
E_{x}=E \sin \left(\omega_{e} t-\delta\right)
\end{gathered}
$$

Here, $\mathrm{E}$ is the magnitude of the back EMF, we is the electrical angular velocity, and $\delta$ is the angle between the two half windings.

The cumulative back EMF, Ecum, which is equal to the back EMF of the basic three-phase machine can be represented by (4).

$$
E_{\text {cum }}=E \sin \left(\omega_{e} t\right)+E \sin \left(\omega_{e} t-\delta\right)
$$

The differential back EMF of the machine after winding switching, Edif, is shown below in (5).

$$
E_{d i f}=E \sin \left(\omega_{e} t\right)-E \sin \left(\omega_{e} t-\delta\right)
$$

The ratio of the net back EMF of the basic three-phase machine to the net back EMF of the machine in the differential mode is the net reduction in the voltage drop in terms of the back EMF of the machine Efw and can be represented by (6).

$$
E_{f w}=\frac{E_{c u m}}{E_{d i f}}
$$

Eqs. (4) and (5) show that the net reduction in the back EMF of the machine is dependent upon the angle between the two half windings. This fact will be used in the proposed concept of phase swapping for the multiple wide speed range operations of a PM machine.

Similarly, the ratio of the inductive voltage drops in cumulative mode to the inductive voltage drop in differential mode can be generalized by general inductance equations of the two coils connected in series with same polarity in cumulative mode and opposite polarity in differential mode.

$$
L_{n e t}=L_{a}+L_{x} \mp 2 L_{a x}
$$

Where Lnet is the net inductance of the resultant coil

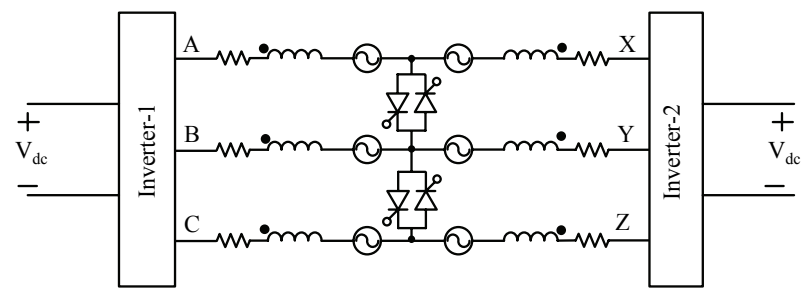

Fig. 1. Drive circuit for flux weakening using winding switching

obtained by connecting two coils in series. La is the inductance of phase-A, Lx is the inductance of phase- $\mathrm{X}$ Lax is the mutual coupling of phase-A and phase-X. Whereas mutual inductance between phase-A and phase- $X$ of the machine can be represented as (8).

$$
L_{a x}=L_{a} \cos (\delta)
$$

where $\delta$ is the angle between phase-A and phase-X.

However, the resistive voltage drop in cumulative and differential mode remains the same. Furthermore, the resistive voltage drop for well-designed large machines are ignored for simplicity of analysis. Hence, resistive voltage drop is ignored for the winding switching technique while calculating the net voltage drop in cumulative mode and the differential mode.

In order to achieve the above mentioned flux weakening operation using winding switching, suitable drive topologies have been proposed $[14,15]$. The machine is operated with a dual inverter topology with the drive circuit shown in Fig. 1.

The machine is operated in a dual three-phase machine configuration with currents entering at the dotted ends of the machine winding in the cumulative mode. Hence, the MMF of both half windings are positive and the machine operates in the normal operation with a strong flux. Thyristros establish neutral connections which are turned off for winding switching. The machine operation is converted into the open winding configuration and the currents enter at the dotted ends of the $\mathrm{ABC}$ winding and leave at the dotted ends of the XYZ winding. Hence, the MMF of the $\mathrm{ABC}$ winding is positive whereas the MMF of the $\mathrm{XYZ}$ winding is negative, resulting in the flux weakening operation. The flux of the machine is reduced by at least Efw calculated by (6). Hence, the machine should achieve a final speed of Efw times the base speed of the machine (Nfw) due to this flux weakening. However, for winding switching, not only is the flux of the machine reduced by Efw but also the machine configuration is converted into an open winding configuration. Inverters need to overcome the phase voltage in the open winding configuration to inject a proper current compared to the line voltages in a neutral connected machine. The phase voltage is $\sqrt{3}$ times lower than the line voltage. Hence, the inverter faces a $\sqrt{3}$ times lower voltage in the differential 
mode in addition to flux weakening of the machine. Therefore, the speed of the machine can be increased by $\sqrt{3}$ times further in addition to the flux weakening speed (Nfw) due to the open winding configuration. The final achievable speed of the machine can therefore be calculated using Eq. (9) [14].

$$
N_{\text {final }}=\sqrt{3} N_{f w}
$$

Where Nfinal is the final achievable speed of the machine and $\mathrm{Nfw}$ is the flux weakening speed of the machine defined as fw times the base speed of the machine. It should be noted that winding switching yields flux weakening without using the negative d-axis current. Hence, the speed of the machine calculated by Eq. (9) is determined without applying the negative d-axis current. Therefore, the speed of the machine can be further increased using the negative d-axis current beyond the speed of the machine calculated by Eq. (9). However, this increment of the speed of the machine depends upon its inherent flux weakening capability using the negative daxis current [15].

\section{Proposed Concept of Phase Swapping}

This paper proposes a novel phase swapping concept which takes advantage of the natural tendency of a machine design to be operated with different displacement angles between two 3-phase windings of a dual three-phase machine. As stated earlier, the flux weakening range in the winding switching technique depends on the displacement angle between two 3-phase windings of the machine. Therefore, the multiple flux weakening ranges of the machine are possible using the proposed concept of phase swapping without altering any hardware. A 2-pole, 24-slot machine design with surface mounted permanent magnets is proposed where each slot is $\pi / 12$ radians apart. This machine design can utilize the proposed concept of phase

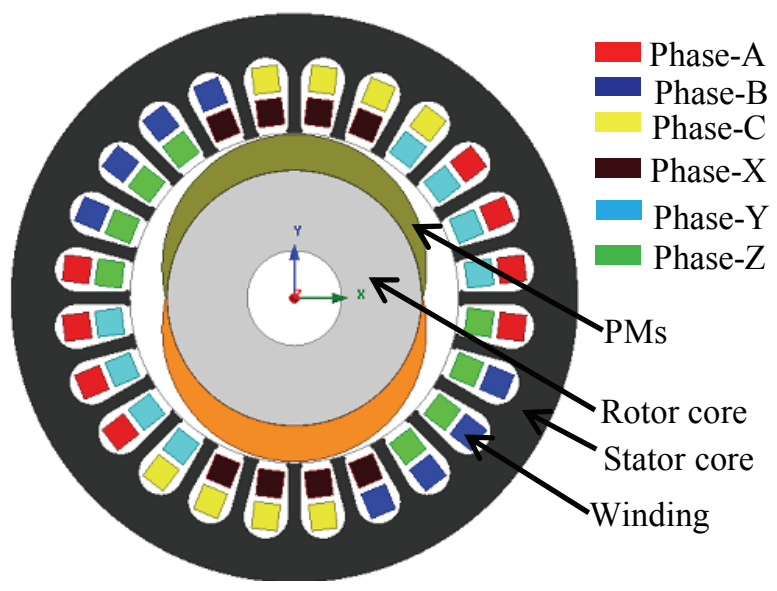

Fig. 2. Simulation model of the machine

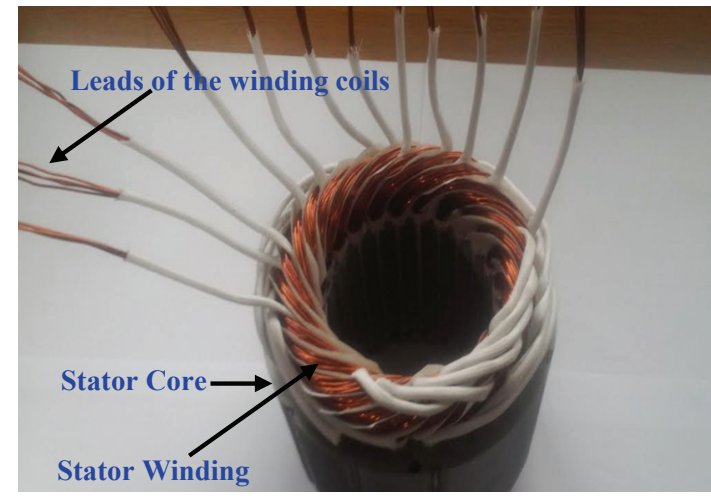

Fig. 3. Stator of the experiment machine

swapping. When the winding of a basic three-phase machine is divided into two equal half windings, a dual three-phase machine results as shown in Fig. 2.

There are twelve leads coming out of the machine due to the six phase configurations at this point, as shown in the stator of the experiment machine in Fig. 3. These leads can be assigned different phases such that $5 \pi / 12, \pi / 4$, and $\pi / 12$ radians apart $\mathrm{ABC}$ and $\mathrm{XYZ}$ windings can be achieved. The resultant machine models with $5 \pi / 12, \pi / 4$, and $\pi / 12$ radians apart windings are referred to as model-I, model-II, and model-III, respectively, throughout the remainder of this paper.

\subsection{Model-I}

The model-I machine winding configuration is achieved if the leads of the winding coils are assigned phases such that the resultant $\mathrm{ABC}$ and $\mathrm{XYZ}$ windings are $5 \pi / 12$ radians apart. Fig. 4 shows the phase assignment to the leads of the winding coils on the stator periphery for model-I. It is clear that the axis of phase $A$ is $5 \pi / 12$ radians apart from the axis of phase $\mathrm{X}$. These windings can be connected in the cumulative mode to obtain basic threephase machine normal operation or in differential mode to obtain flux weakening operation (10-14).

$$
\begin{gathered}
E_{a}=E \sin \left(\omega_{e} t\right) \\
E_{x 1}=E \sin \left(\omega_{e} t-5 \pi / 12\right) \\
E_{c u m 1}=1.5867 E \sin \left(\omega_{e} t-5 \pi / 24\right) \\
E_{d i f 1}=1.2175 E \sin \left(\omega_{e} t+7 \pi / 24\right) \\
E_{f w 1}=\frac{\left|E_{\text {cum } 1}\right|}{\left|E_{\text {dif } 1}\right|}=\frac{1.5321}{1.234} \cong 1.30
\end{gathered}
$$

Here, subscript ' 1 ' represents model-I.

Similarly, the reduction in net inductive voltage drop while switching from cumulative to differential mode can be calculated using (15-18).

$$
L_{\text {cum } 1}=L_{a}+L_{x}+2 L_{a} \cos (5 \pi / 12)
$$




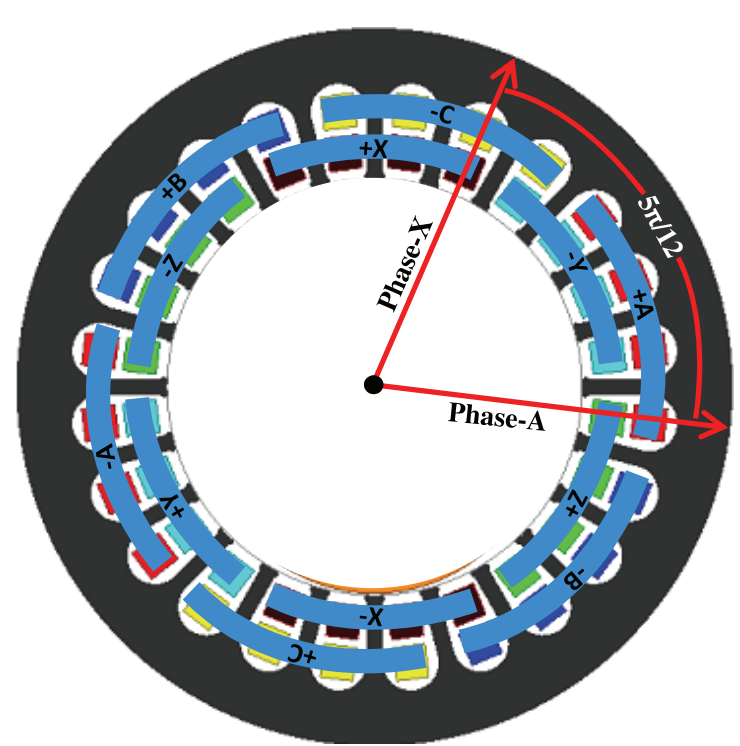

Fig. 4. Winding assignment for model-I

Where Lcum1 is the net inductance in cumulative mode. For a balanced machine, the phase inductances are equal. Considering phase inductance as $\mathrm{L}$, the net inductance of the machine in cumulative mode can be calculated as (16).

$$
L_{\text {cum } 1}=L+L+2 L \times 0.25=2.5 L
$$

Similarly, net inductance of phase $\mathrm{A}$ and phase $\mathrm{X}$ in differential mode can be calculated as (17).

$$
L_{d i f 1}=1.5 L
$$

Ratio of the inductive voltage drop in cumulative mode to the ratio of the inductive voltage drop in differential mode can be calculated as (18).

$$
L_{f w 1}=2.5 L / 1.5 \mathrm{~L} \cong 1.67
$$

Eq. (14) and (18) show that the net voltage drop reduces by at least 1.30 time while switching from cumulative mode to the differential mode.

\subsection{Model-II}

The output leads of the winding coils can be reassigned to achieve a different dual three-phase machine where the $\mathrm{ABC}$ and $\mathrm{XYZ}$ windings are $\pi / 4$ radians apart. This results in the model-II winding configuration shown in Fig. 5. It is obvious from this figure that the axis of phase $\mathrm{A}$ is $\pi / 4$ radians apart from the axis of phase X. Moreover, it is also clear that the physical placement of the coils on the stator of the machine does not change when converting from the model-I to model-II winding configuration. The net reduction in back EMF voltage drop while switching from cumulative mode to the differential mode of operation can be calculated using (19-23).

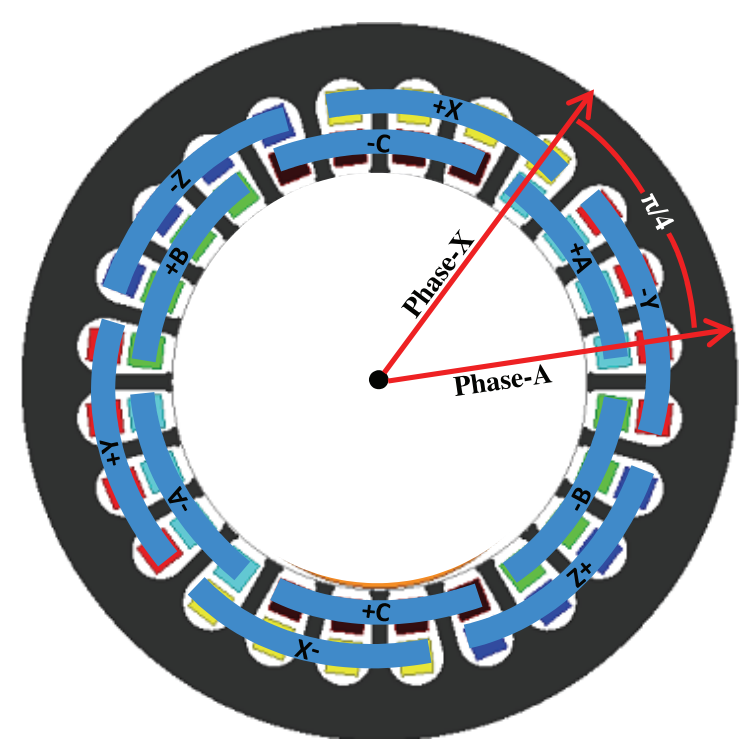

Fig. 5. Winding assignment for model-II

$$
\begin{gathered}
E_{a}=E \sin \left(\omega_{e} t\right) \\
E_{x 2}=E \sin \left(\omega_{e} t-\pi / 4\right) \\
E_{c u m 2}=1.8477 E \sin \left(\omega_{e} t-\pi / 8\right) \\
E_{\text {dif } 2}=0.7654 E \sin \left(\omega_{e} t+3 \pi / 8\right) \\
E_{f w 2}=\frac{\left|E_{\text {cum } 2}\right|}{\left|E_{\text {dif } 2}\right|}=\frac{1.8477}{0.7654} \cong 2.41
\end{gathered}
$$

Similarly, the reduction in inductive voltage drop while switching from cumulative mode to the differential mode can be calculated using (24-27)

$$
\begin{gathered}
L_{\text {cum } 2}=L_{a}+L_{x}+2 L_{a} \cos (\pi / 4) \\
L_{\text {cum } 2}=L+L+2 L \times 0.71=3.42 L \\
L_{\text {dif } 2}=0.58 L \\
L_{f w 2}=3.42 L / 0.58 L
\end{gathered}
$$

Eq. (23) and (27) show that the net voltage drop on model-II reduces by at least 2.41 times while switching from cumulative mode to the differential mode. Although the inductive voltage drop shows significant reduction compared to back EMF of the machine, however, the overall voltage drop depends upon ratio of the back EMF voltage drop to the inductive voltage drop and varies from machine to machine. Moreover, the surface mounted permanent magnet machines are well known for their low inductance profile. Hence, in general. The back EMF of the machine is the major contributor in the net voltage drop of the surface mounted permanent magnet motors.

\subsection{Model-III}

There is yet another way to assign different phases to the output leads of this machine, as shown in Fig. 6. The axis of phase $\mathrm{A}$ is $\pi / 12$ radians apart from the axis of phase $\mathrm{X}$. 
Hence, in this winding configuration, the $\mathrm{ABC}$ and $\mathrm{XYZ}$ windings are $\pi / 12$ radians apart. The net back EMF voltage drop while switching from cumulative mode to differential mode can be calculated using (28-32).

$$
\begin{gathered}
E_{a}=E \sin \left(\omega_{e} t\right) \\
E_{x 3}=E \sin \left(\omega_{e} t-\pi / 12\right) \\
E_{\text {cum } 3}=1.9829 E \sin \left(\omega_{e} t-\pi / 24\right) \\
E_{\text {dif } 3}=0.2611 E \sin \left(\omega_{e} t+11 \pi / 24\right) \\
f w_{3}=\frac{\left|E_{\text {cum } 2}\right|}{\left|E_{\text {dif } 2}\right|}=\frac{1.9829}{0.2611} \cong 7.59
\end{gathered}
$$

It is obvious that there is no change of the stator winding coils in all three models. Only the output leads of the winding coils are assigned different phases to achieve the three different models with three different flux weakening ranges. The phase assignment to the output leads of the winding coils can be configured through the DSP program to drive the machine using inverters. Moreover, the location of phases on the stator periphery is different for all three machine models. This information is already available from machine structure while driving the machine. Hence,

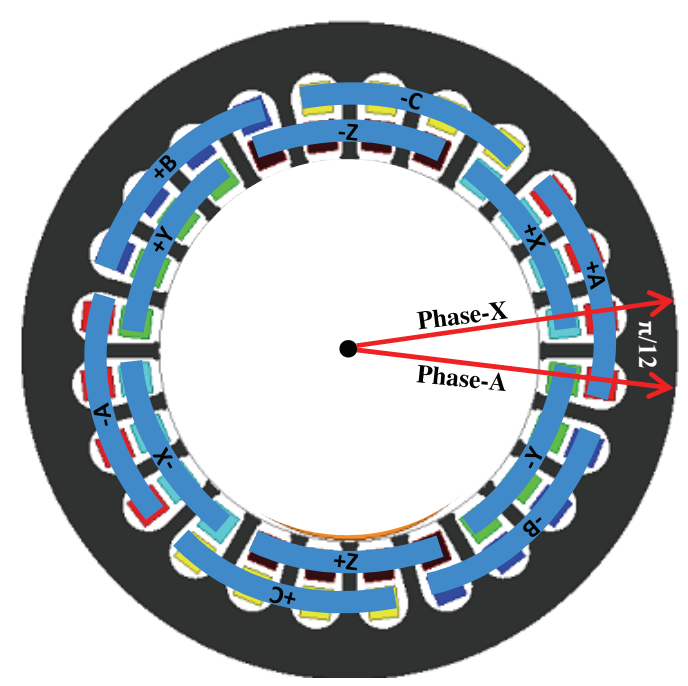

Fig. 6. Winding assignment for model-III

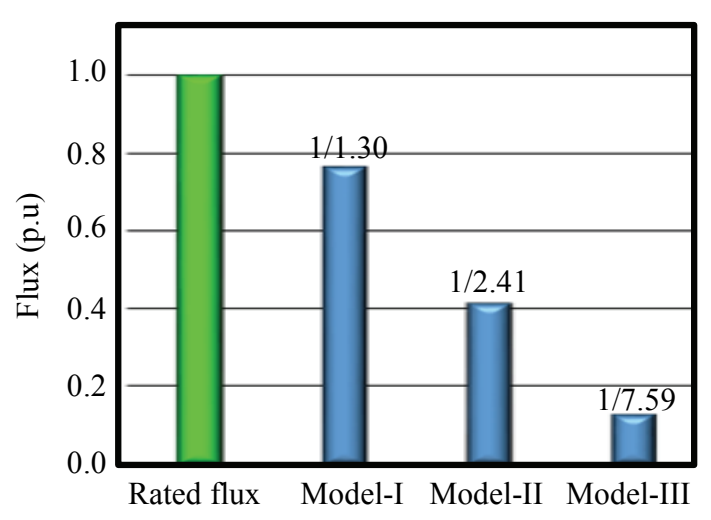

Fig. 7. Flux weakening capability of machine models proper phase shift can be amended in the rotor position measured by the position encoder to inject proper currents into the machine winding while operating under different models configuration.

The proposed concept of phase swapping resulted in three different displacement angles $(5 \pi / 12, \pi / 4$, and $\pi / 12)$ between the two half windings of the machine. Hence, the same machine design can achieve three different flux weakening ranges $(1.30,2.41$, and 7.59$)$ without altering any hardware of the machine. Fig. 7 shows the flux weakening capability of the machine models compared to the rated flux of the machine using the proposed phase swapping concept.

\section{Machine Operation}

The variable speed operation requirements of an electrical machine depend upon the load characteristics and can be divided in two sub categories depending on the machine operation over its entire speed range.

- Discrete step operation

- Continuous operation

There are certain applications which require discrete step speed operations. These applications either operate in a low speed mode or in a high speed mode such as washing machines. On the other hand, there are some applications which require continuous operation over the entire speed range such as electric and hybrid vehicles. It will be demonstrated in this study that the proposed concept of phase swapping is equally valid for both of the applications mentioned above. The specifications of the machine used for verification of the proposed concept are given in Table 1.

Table 1. Machine specifications

\begin{tabular}{c|c|c}
\hline Item & Value & Unit \\
\hline Number of slots & 24 & - \\
\hline Number of poles & 2 & - \\
\hline Stator outer diameter & 120 & $\mathrm{~mm}$ \\
\hline Stator inner diameter & 68 & $\mathrm{~mm}$ \\
\hline Magnet thickness & 5.5 & $\mathrm{~mm}$ \\
\hline Air gap thickness & 1 & $\mathrm{~mm}$ \\
\hline Magnet Br & 1.15 & $\mathrm{~T}$ \\
\hline
\end{tabular}

\section{Discrete Step Operation}

All three machine models are validated for the discrete step operation of the machines using simulation and experimental results in this section.

\subsection{Model-I Operation}

Model-I in the proposed machine design has dual three- 


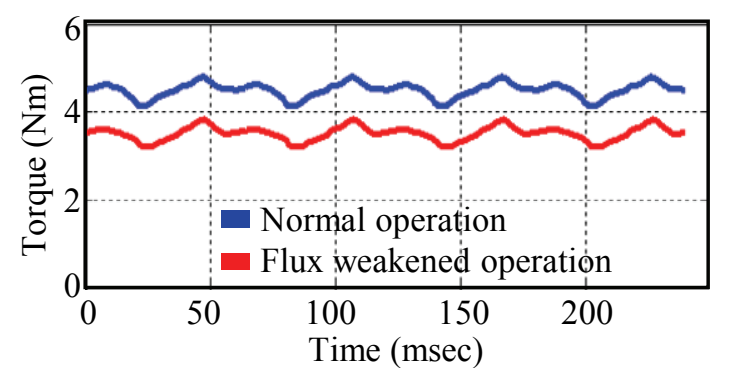

(a)

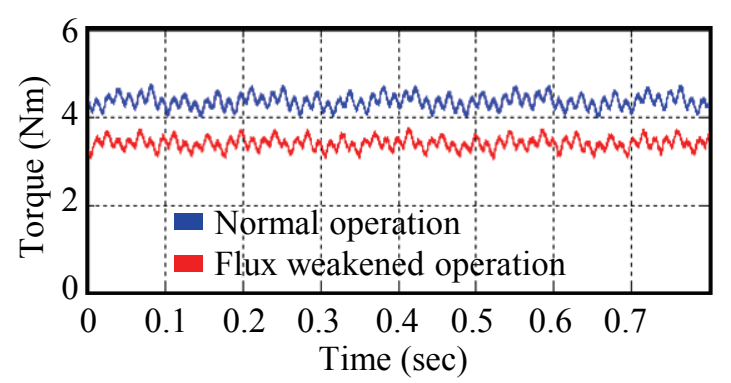

(b)

Fig. 8. Discrete step operation of model-I: (a) simulation and (b) experimental results

phase winding displaced by $5 \pi / 12$ radians and a flux weakening range of 1.3 . The rated speed of the machine was selected to be $700 \mathrm{rpm}$ with a rated phase current of 4 Arms. When the basic three-phase machine model was simulated using Maxwell 2D software, it generated an output torque of $4.51 \mathrm{Nm}$. However, when the machine was simulated in the flux weakening mode, the machine generated a torque of $3.51 \mathrm{Nm}$. This resulted in a flux weakening range of 1.28 which agrees well with the calculated flux weakening range of 1.30. A prototype machine was also tested under the same conditions. The normal torque of the machine was measured to be $4.36 \mathrm{Nm}$ whereas the flux weakened torque was measured to be 3.23 $\mathrm{Nm}$, resulting in a flux weakening range of 1.35 . The simulation and experimental results for model-I under the discrete step operation are depicted in Fig. 8 (a) and (b), respectively.

\subsection{Model-II Operation}

For model-II operation, the dual three-phase windings are displaced by $\pi / 4$ radians and the flux weakening range of this machine model was calculated to be 2.41 . When the machine was simulated under the rated conditions, the conventional three-phase machine generated an output torque of $5.17 \mathrm{Nm}$. The simulated output torque of the machine was found to be $2.20 \mathrm{Nm}$ in the flux weakened operation. Hence, the simulated flux weakening range of the machine obtained was 2.35. The prototype machine was also tested under the same conditions. The output torques of the machine during normal operation and the flux weakened operation were measured to be $5.05 \mathrm{Nm}$ and

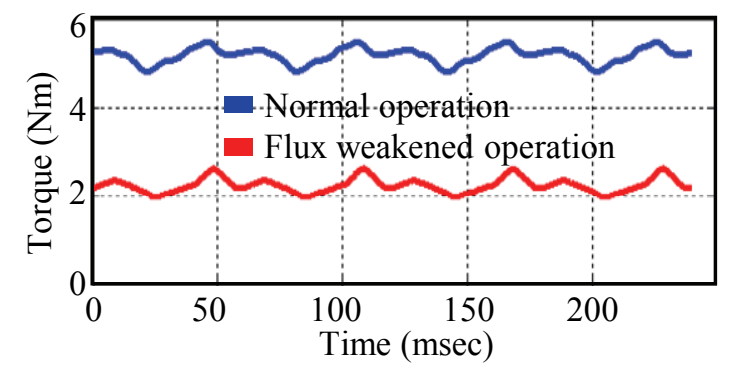

(a)

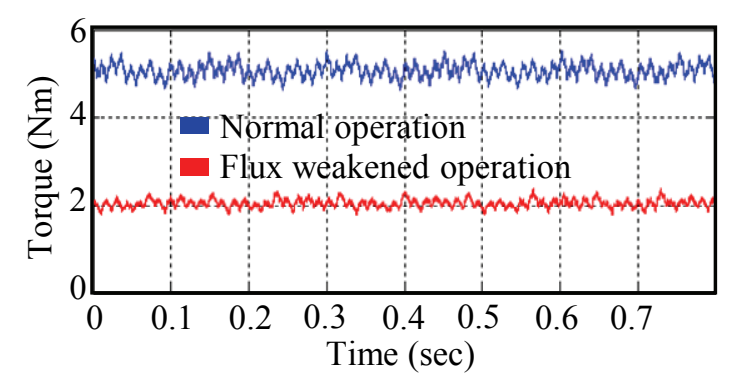

(b)

Fig. 9. Discrete step operation of model-II: (a) simulation and (b) experimental results

2.07 Nm, respectively. The experimented flux weakening range of the machine was measured to be 2.43 . The simulation and experimental results for normal and flux weakened operation of the machine with the model-II winding assignment are depicted in Fig. 9(a) and (b), respectively.

\subsection{Model-III Operation}

In the model-III winding assignment, the $\mathrm{ABC}$ and $\mathrm{XYZ}$ windings are $\pi / 12$ radians apart and a flux weakening range of 7.59. The machine generated an output torque of 5.53 $\mathrm{Nm}$ when simulated under normal conditions. Under flux weakening conditions, the machine generated an output torque of $0.75 \mathrm{Nm}$. Hence, the simulated flux weakening range of the machine is 7.37 . The prototype machine generated an output torque of $5.38 \mathrm{Nm}$ under normal conditions with the model-III winding assignment. However, the machine generated an output torque of $0.68 \mathrm{Nm}$ under flux weakening operation, resulting in a flux weakening range of 7.91. The simulation and experimental results for machine operation with the model-III winding assignment are shown in Fig. 10(a) and (b), respectively.

The torque per ampere ratios of the three machine models are shown in Fig. 11(a) and (b) for the simulation and experimental cases, respectively. It is obvious from these figures that the same phase current can generate a higher output torque in the normal mode compared to the flux weakened case. Another interpretation that can be made from Eqs. (12), (21), and (30) is that the cumulative back EMF of the machine is higher for the case where the angle between two half windings is smaller. Therefore, the 
Table 2 Flux weakening ranges obtained using phase swapping

\begin{tabular}{c|c|c|c}
\hline $\begin{array}{c}\text { Machine } \\
\text { Model }\end{array}$ & $\begin{array}{c}\text { Displacement } \\
\text { angle }\end{array}$ & $\begin{array}{c}\text { Simulated } \\
\text { fw }\end{array}$ & $\begin{array}{c}\text { Experimented } \\
\text { fw }\end{array}$ \\
\hline I & $5 \pi / 12$ & 1.28 & 1.35 \\
\hline II & $\pi / 4$ & 2.35 & 2.43 \\
\hline III & $\pi / 12$ & 7.37 & 7.91 \\
\hline
\end{tabular}

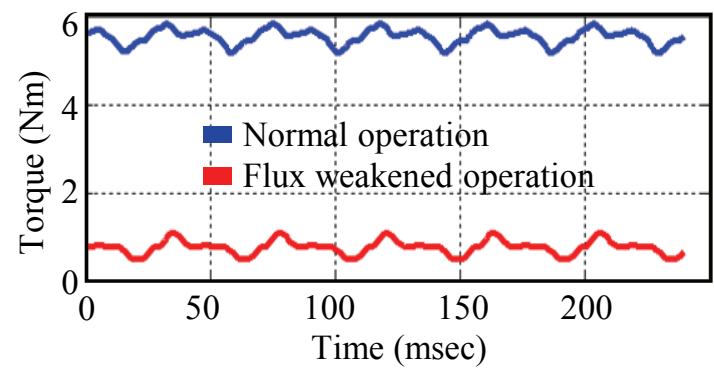

(a)

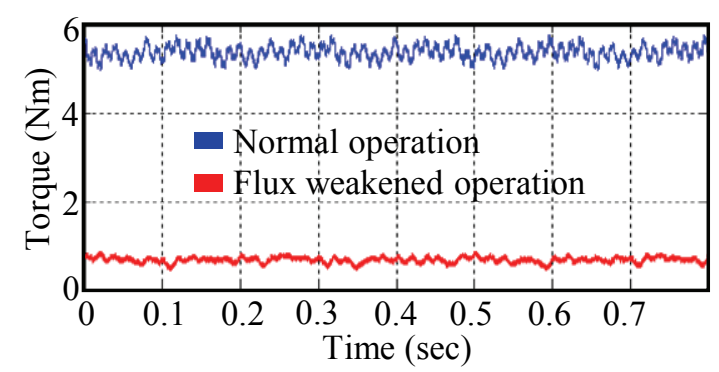

(b)

Fig. 10. Discrete step operation of model-II: (a) simulation and (b) experimental results

same phase current can generate a higher output torque for model-II compared to model-I and model-III compared to model-II, which is obvious in Figs. 8-10.

A summary of the three machine models obtained from the proposed machine design using the proposed concept of phase swapping is presented in Table 2.

\section{Continuous Operation}

Some applications such as electric and hybrid vehicles require continuous operation of electric machines from zero to maximum speed. In this case, an electric machine first operates from zero speed to its maximum speed in normal operation. The windings of the machine are then switched to achieve flux weakening operation so as to reduce the internal voltage of the machine. Hence, the speed of the machine is further increased due to flux weakening using winding switching and the $\sqrt{3}$ times extra voltage due to the open winding configuration. The thyristors in Fig. 1 are turned off to achieve this operation condition.

Model-I was used to validate the continuous operation of

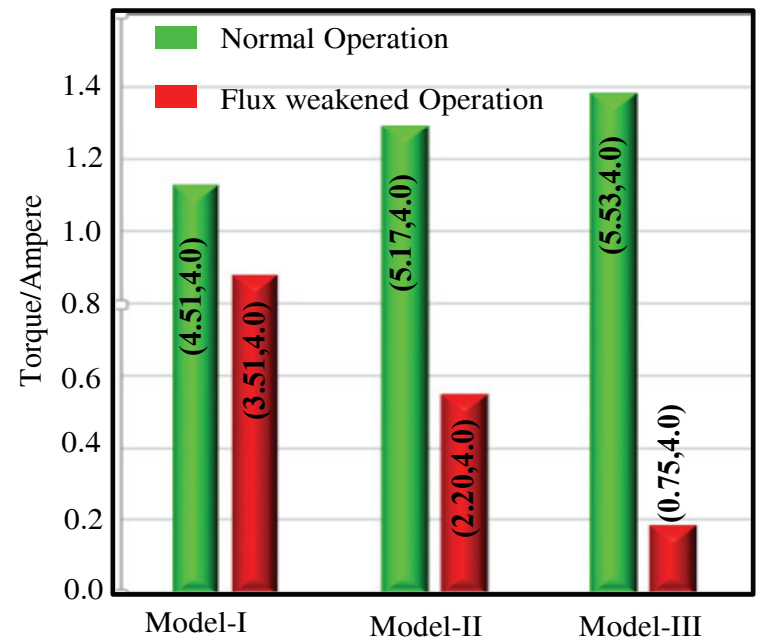

(a)

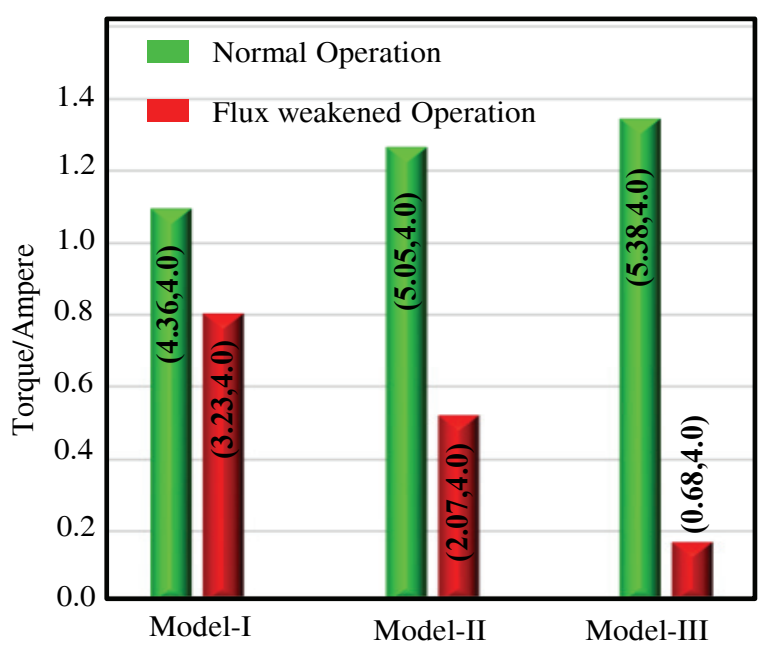

(b)

Fig. 11. Torque per ampere ratios of the machine models: (a) simulation and (b) experimental results

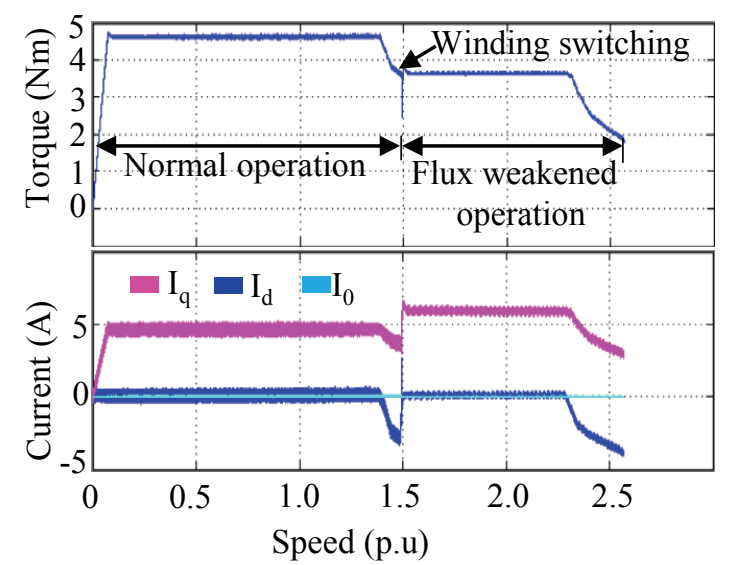

Fig. 12. Simulated continuous operation of the machine

the machine over its entire speed range. SIMULINK simulations were carried out for this purpose. Fig. 12 shows the results of the operation of the machine over its 
entire speed range. It was assumed that one p.u is the rated speed of the conventional three-phase machine which is achieved through one p.u inverter voltage. However, when the conventional three-phase machine is converted into a six-phase machine, the back EMF of the machine is reduced due to the reduction of the number of turns per phase of the six-phase machine compared to the basic three-phase machine. It is obvious from Eqs. (10-12) that the back EMF of the basic three-phase machine (Ecum1) is 1.58 times higher than the phase back EMF of the sixphase machine (Ea). Hence, the internal voltage of the machine is reduced but the inverter voltage is maintained to be one p.u. Therefore, the six-phase machine is operated beyond one p.u speed in normal operation, as shown in Fig. 12. When the machine reaches its maximum speed limit in the normal mode, a negative d-axis current is utilized to further speed up the machine. However, the negative d-axis current increases the speed of the machine at the cost of its output torque. The negative $\mathrm{d}$-axis current continues to increase until the machine torque was reduced by a factor of $1 / 1.30$, i.e., flux weakening by winding switching. The

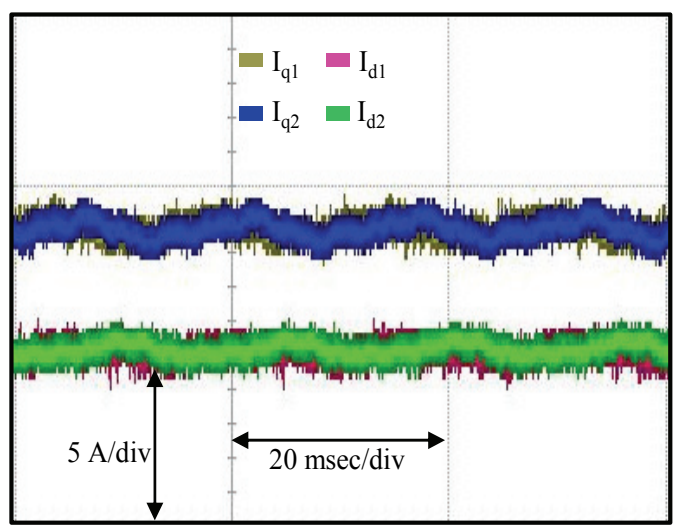

(a)

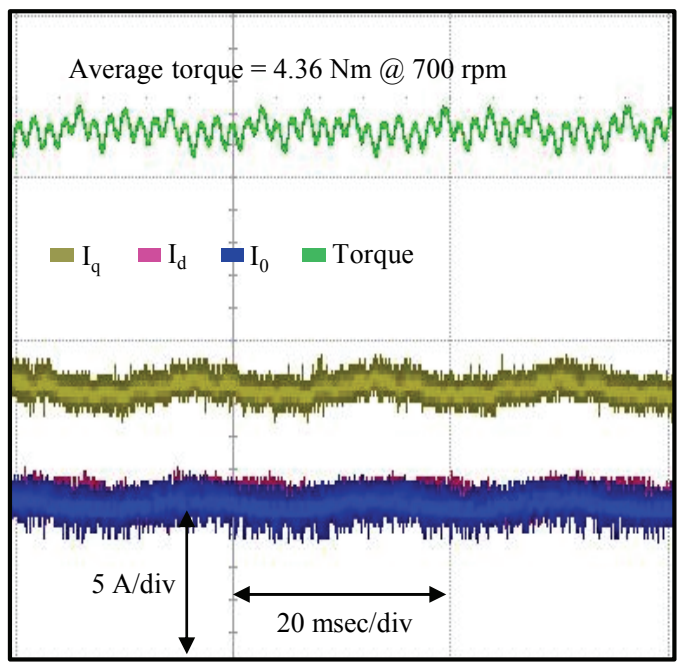

(b) virtue of flux weakening using winding switching is that it achieves flux weakening by reversing the polarity of the $\mathrm{XYZ}$ winding and does not utilize the negative d-axis current. This phenomenon is also obvious in Fig. 12 where at winding switching, the negative $\mathrm{d}$-axis current was removed. Application of a negative d-axis current before winding switching was also necessary to reduce the torque of the machine by a factor of $1 / \mathrm{Efw}$ to avoid any steady state torque transient after winding switching. If the negative $d$-axis current was not applied, the torque of the machine would decrease by $1 / 1.30$ abruptly at the winding switching instant and there is a large transient in the continuous operation of the machine in terms of the torque and winding currents. Hence, the torque of the machine was reduced using the negative d-axis current to a magnitude that the machine could maintain after winding switching. There is still a transient in the machine operation at the winding switching instant, but it is not

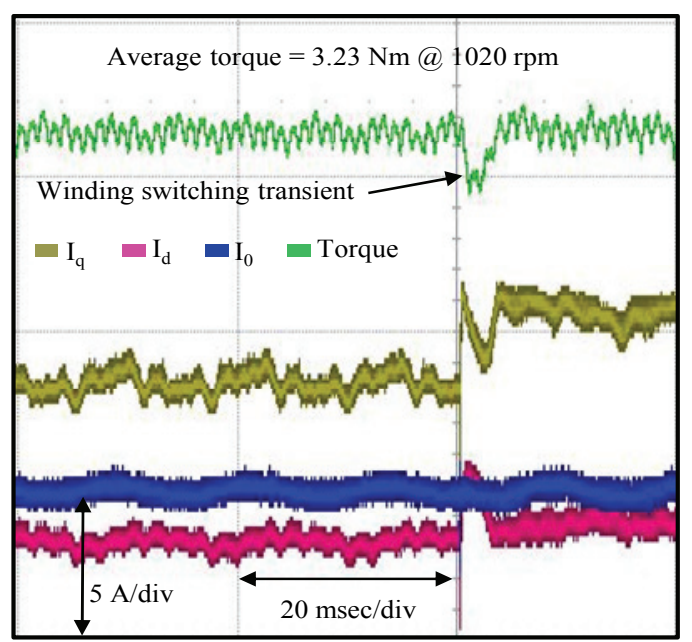

(c)

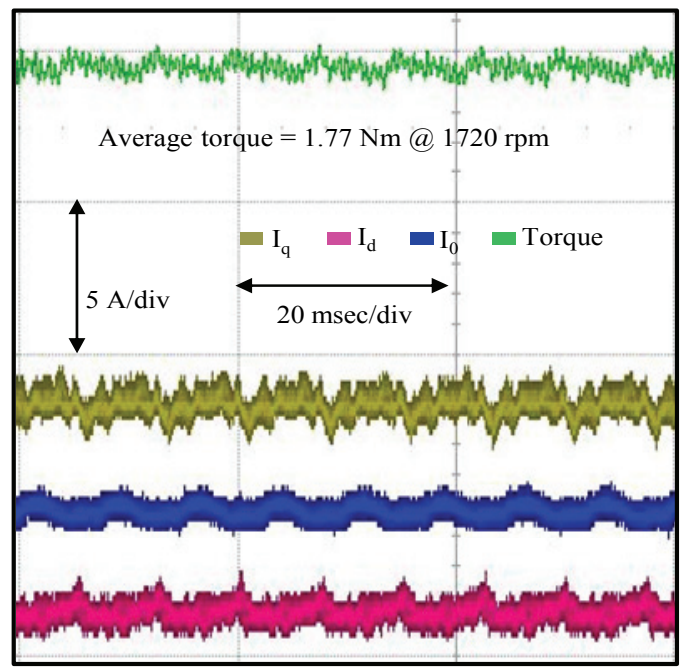

(d)

Fig. 13. Experimental results of the (a) balanced operation of the two inverters; (b) steady state operation in the normal mode; (c) winding switching transient, and (d) steady state operation in the flux weakened mode 
significant to jeopardize the continuous operation of the machine. After winding switching, the machine operation is converted into an open winding configuration. It can maintain its constant torque operation by $\sqrt{3}$ times the $\mathrm{Nfw}$ according to Eq. (9). The machine should achieve a final speed of 2.25 p.u $(\sqrt{3} \times 1.30)$ according to Eq. (9). However, the machine achieved a final speed of 2.57 p.u due to the application of the negative d-axis current again at the end.

Experiments were also conducted to validate the analytical and simulation behaviors of the machine. In the experiments, it was not possible to obtain a continuous graph of the machine currents and torque over the entire speed range, as shown in Fig. 13. However, the currents and torque of the machine were measured at all important points to demonstrate the successful implementation of the continuous operation of the machine. These important points included steady state operation during normal operation, winding switching transient, and the final steady state operation during flux weakened operation of the machine.

Dual inverter voltage controlled machines face the problem of imbalance current sharing between the two power sections [17-19]. On the other hand, current regulated systems have been demonstrated to possess superior current control compared to the voltage controlled system $[20,21]$. Hence, a current controlled system was utilized in this research to avoid any imbalance currents sharing of the two power sections of the machine. Fig. 13(a) shows the balanced operation of the two inverters while feeding the two half $\mathrm{ABC}$ and $\mathrm{XYZ}$ windings. Therefore, only dq0 currents are shown in Fig. 13(b)-(d) instead of the dq01 and dq02 currents from inverter-1 and inverter-2, respectively.

Initially, the machine was operated in the constant torque region with $\mathrm{Id}=0$ control with a rated torque of $4.36 \mathrm{Nm}$, as shown in Fig. 13(b). A negative d-axis current was applied to further increase the speed of the machine at the end of the constant torque region. This increase of the speed was achieved at the cost of its output torque. The machine speed continued to increase until the torque of the machine was reduced by $1 / 1.35$ times the rated torque of the machine. At this point, the windings of the machine were switched to operate the machine in the flux weakened mode and the negative d-axis current was removed, as shown in Fig. 13(c). It is obvious from this figure that the machine was operating with a negative d-axis current before winding switching which was removed at the winding switching instant.

Operation of the machine was converted into the open winding configuration at this point. Hence, the machine maintained its torque for its speed from $\mathrm{Nfw}$ to $\sqrt{3}$ times $\mathrm{Nfw}$. A negative d-axis current was again applied to further increase the speed of the machine. The final operation point of the machine was determined to be $1720 \mathrm{rpm}$ with a torque of $1.77 \mathrm{Nm}$ with one p.u power. Hence, the machine increased its speed by about 2.45 times its rated speed while operating with the model-I winding configuration.

\section{Conclusion}

In this study, we propose a novel concept of phase swapping which enables multiple wide speed range operations of a non-salient PM machine without altering any hardware of the machine. The proposed concept generalizes machine utilization in any application requiring different speed range operations. Also, the proposed concept is equally valid for the discrete step operation as well as the continuous operation of the machine. Analytical, simulation, and experimental results validated the proposed concept.

\section{Acknowledgements}

This work was supported in part by the BK21PLUS Program through the National Research Foundation of Korea within the Ministry of Education, and in part by the National Research Foundation of Korea (NRF) grant funded by the Korea government (Ministry of Science) (No.NRF-2013R1A2A2A01068022).

\section{References}

[1] S. Atiq, T. A. Lipo, and B. I. Kwon, "Novel field weakening technique for Surface Mounted Permanent Magnet machine using Current Regulated Voltage Source Inverters", in Power Electronics, Electrical Drives, Automation and Motion (SPEEDAM), 2014 International Symposium on, pp. 836-84, 2014.

[2] A. M. El-Refaie, and T. M. Jahns, "Optimal flux weakening in surface PM machines using concentrated windings", in Industry Applications Conference, 2004. 39th IAS Annual Meeting. Conference Record of the 2004 IEEE, pp. 1038-1047 vol. 2 , 2004.

[3] R. F. Schiferl, and T. A. Lipo, "Power capability of salient pole permanent magnet synchronous machines in variable speed drive applications", IEEE Transactions on Industry Applications, vol. 26, pp. 115-123, 1990.

[4] A. G. Jack, B. C. Mecrow, P. G. Dickinson, D. Stephenson, J. S. Burdess, J. N. Fawcett, et al., "Permanent magnet machines with powdered iron cores and pre-pressed windings", in Industry Applications Conference. Thirty-Fourth IAS Annual Meeting. Conference Record of the 1999 IEEE, pp. 97-103 vol. 1, 1999.

[5] R. Krishnan, "Permanent Magnet Synchronous and Brushless DC Machine Drives ": CRC Press, Taylor \& Francis Group, LLC, Baco Raton, 2010.

[6] A. M. El-Refaie, T. M. Jahns, P. J. McCleer, and J. W. McKeever, "Experimental verification of optimal flux weakening in surface PM Machines using concentrated windings", IEEE Transactions on Industry 
Applications, vol. 42, pp. 443-453, 2006.

[7] A. M. E. Refaie, and T. M. Jahns, "Optimal flux weakening in surface PM machines using fractionalslot concentrated windings", IEEE Transactions on Industry Applications, vol. 41, pp. 790-800, 2005.

[8] L. Chong, and M. F. Rahman, "Saliency ratio derivation and optimisation for an interior permanent magnet machine with concentrated windings using finite-element analysis", IET Electric Power Applications, vol. 4, pp. 249-258, 2010.

[9] T. Gundogdu, and G. Komurgoz, "Implementation of fractional slot concentrated winding technique to large salient-pole synchronous generators \&amp; development with permanent magnets", Electric Power Systems Research, vol. 105, pp. 57-70, 2013.

[10] J. J. Lee, W. H. Kim, J. S. Yu, S. Y. Yun, S. M. Kim, J. J. Lee, et al., "Comparison between concentrated and distributed winding in IPMSM for traction application", in Electrical Machines and Systems (ICEMS), 2010 International Conference on, pp.1172-1174, 2010.

[11] J. A. Tapia, F. Leonardi, and T. A. Lipo, "Consequentpole permanent-magnet machine with extended fieldweakening capability", IEEE Transactions on Industry Applications, vol. 39, pp. 1704-1709, 2003.

[12] H. Hong, and C. Liuchen, "Electrical two-speed propulsion by machine winding switching and its control strategies for electric vehicles", IEEE Trans-actions on Vehicular Technology, vol. 48, pp. 607-618, 1999.

[13] Z. Jiancheng, F. Youtong, H. Xiaoyan, and Z. Jian, "Design of in-wheel permanent magnet synchronous machine with concentrated fractional-slot winding and winding switching technology", in Electrical Machines and Systems (ICEMS), 2013 International Conference on, pp. 1202-1206, 2013.

[14] S. Atiq, T. A. Lipo, and B.I. Kwon, "Experimental verification of winding switching technique to enhance maximum speed operation of surface mounted permanent magnet machines", IET Electric Power Applications, vol. 10, 2016.

[15] S. Atiq, T. A. Lipo, and B. I. Kwon, "Wide Speed Range Operation of Non-Salient PM Machines", IEEE Transactions on Energy Conversion, vol. PP, pp. $1-1,2016$.

[16] S. Hemmati, and T. A. Lipo, "Field weakening of a surface mounted permanent magnet machine by winding switching", in Power Electronics, Electrical Drives, Automation and Motion (SPEEDAM), 2012 International Symposium on, pp. 736-740, 2012.

[17] R. Bojoi, F. Farina, M. Lazzari, F. Profumo, and A. Tenconi, "Analysis of the asymmetrical operation of dual three-phase induction machines", in Electric Machines and Drives Conference, IEEE International, pp. 429-435 vol.1, 2003.

[18] Z. Changpan, S. Jianyong, Y. Guijie, and X. Nianwei, "Four-dimension current vector control for dual threephase PMSM," in Electrical Machines and Systems (ICEMS), 2014 17th International Conference on, 2014, pp. 1596-1600.
[19] J. Karttunen, S. Kallio, P. Peltoniemi, P. Silventoinen, O. Pyrh, et al., "Decoupled Vector Control Scheme for Dual Three-Phase Permanent Magnet Synchronous Machines", IEEE Transactions on Industrial Electronics, vol. 61, pp. 2185-2196, 2014.

[20] S. Bukhari, S. Atiq, and B.I. Kwon, "Elimination of the Inrush Current Phenomenon Associated with Single-Phase Offline UPS Systems", Energies, vol. 9, p. 96, 2016.

[21] S. S. H. Bukhari, S. Atiq, T. A. Lipo, and B.I. Kwon, "A Cost-Effective, Single-Phase Line-Interactive UPS system that Eliminates Inrush Current Phenomenon for Transformer-Coupled Loads", Journal of Electrical Engineering \& Technology, vol. 11, pp. 675-682 2016.

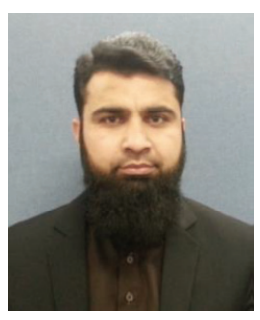

Shahid Atiq He received his B.S and M.S degree in electrical engineering from University of Engineering and Technology Taxila, Pakista and Ph.D degree from Hanyang University South Korea. Currently he is working as an assistant professor in electrical engineering department at Islamia University of Bahawalpur, Pakistan. His research interests include electrical machines design, drive, control and power electronics.

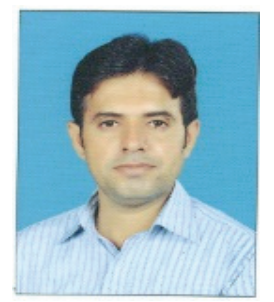

Asif Hussain He received his B.Sc. in electrical engineering from Bahauddin Zakariya University Multan, Pakistan, in 2005 and M.S. in electrical engineering and computer science from Seoul National University, South, Korea, in 2010. He is currently a Ph.D. student in department of Electronic Systems Engineering at Hanyang University, Ansan, Korea. His research interests include electrical machine design, control and power electronics.

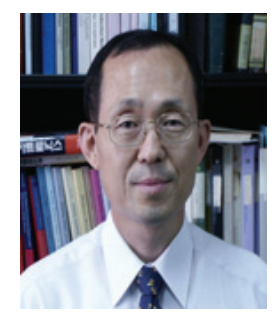

Byung-il Kwon He was born in 1956. He received his B.S. and M.S. in electrical engineering from Hanyang University, Ansan, Korea, and his Ph.D. in electrical engineering from the University of Tokyo, Tokyo, Japan, in 1989 . He was a visiting researcher with the Faculty of Science and Engineering Laboratory, University of Waseda, Tokyo, from 1989 to 2000; a researcher with the Toshiba System Laboratory in 1990; a senior researcher with the Institute of Machinery and Materials Magnetic Train Business in 1991; and a visiting professor with the University of WisconsinMadison, from 2001 to 2002 . He is currently a professor at Hanyang University. His research interests are design and control of electric machines. 